\title{
From critical pedagogy to critical digital pedagogy: a prospective model for the EFL classrooms
}

\author{
Marwa Mohammad Masood \\ English Language Institute, United International University, Dhaka, Bangladesh, and \\ Md. Mahmudul Haque \\ Faculty of Languages and Translation, King Khalid University, \\ Abha, Saudi Arabia and \\ Faculty of Languages and Linguistics, University of Malaya, \\ Kuala Lumpur, Malaysia
}

\begin{abstract}
Purpose - Critical digital pedagogy (CDP) is an emerging field in education. The basic tenet of CDP involves taking learners' experiences into account and engaging them in critical thinking about social oppression. With the outbreak of the unprecedented COVID-19 pandemic, CDP has got more currency and appropriacy in the current paradigm shift in learning and teaching.

Design/methodology/approach - This paper scrutinizes different aspects of CDP including its origins, theoretical underpinnings and its implementation in different contexts. It also critically reviews Freire's (1972) problem-posing education and Morris and Stommel's (2017) model of CDP.

Findings - The article proposes a CDP model based on the previous ones, which includes the core concepts and criteria of CDP and focuses on EFL classrooms.

Research limitations/implications - One of the limitations of CDP is gaining the learners' approval in creating an environment of co-constructing knowledge moving away from traditional practices. In addition to that, the use of new media in the classroom can be intimidating for students and stakeholders alike. The lack of logistic support in many rural, remote and underdeveloped contexts cannot be ignored either

Practical implications - The paper provides recommendations for future research in CDP.

Originality/value - Critical pedagogy (CP) is a teaching approach in which the oppressed are basically focused and teachers and learners construct knowledge together. Recently, with the outbreak of the COVID-19 pandemic, global education had to go online. Consequently, traditional teaching and learning had to undergo a paradigm shift. Along with other changes in traditional teaching and learning practices, there has been a significant change in teaching philosophy. This is how the CDP finds its currency in this emerging unprecedented teaching and learning situation.
\end{abstract}

Keywords Collaborative learning, COVID-19, Critical digital pedagogy, EFL, Learners' agency,

Pedagogy of the Oppressed, Social injustices

Paper type Research paper

\section{Introduction}

Although critical pedagogy (CP) is a familiar and widely known concept, the idea of critical digital pedagogy $(\mathrm{CDP})$ is relatively new in education. $\mathrm{CP}$ is a critical teaching approach which requires teachers and learners to construct knowledge together challenging the existing power dynamics in the traditional classrooms. $\mathrm{CP}$ was originally formed to critically scrutinize social oppressions by engaging the oppressed in dialogic discussions. However, the

(C) Marwa Mohammad Masood and Md. Mahmudul Haque. Published in Saudi Journal of Language Studies. Published by Emerald Publishing Limited. This article is published under the Creative Commons Attribution (CC BY 4.0) licence. Anyone may reproduce, distribute, translate and create derivative works of this article (for both commercial and non-commercial purposes), subject to full attribution to the original publication and authors. The full terms of this licence may be seen at http:// creativecommons.org/licences/by/4.0/legalcode
From CP to critical digital pedagogy 
SJLS

1,1

relevance, popularity and applicability of $\mathrm{CP}$ have extended to language education and for all groups and communities of students with the course of time, and its further expansion has led to its transition into cyberspace.

With the recent outbreak of the COVID-19 pandemic, the global education had to shift online overnight. Consequently, the traditional teaching and learning process underwent a paradigm shift. Along with other changes in traditional teaching and learning practices, significant changes took place in the teaching philosophy of practitioners across the world, and as a result, $\mathrm{CDP}$ can be implemented with a greater degree of success at present. CDP in simple words is the digital form of CP. It is a platform for creating a community of collaborative learners who belong to diverse backgrounds and bring their individual cultural and political experiences to the classroom. In the traditional context of an EFL classroom, the learners play the role of "depositories" and the teachers act as the "depositors" of knowledge. Such practices reflect the operations of the banking system, thus rightly termed by Paulo Freire, the pioneer of $\mathrm{CP}$, as the "banking education" system (Freire, 2000, pp. 73-80). Understandably, such a knowledge transaction system tends to domesticate learners and creates hindrances against the transformation of "school knowledge" into "action knowledge" (Barnes, 1992). The proponents of CDP advocate the inclusion of the entirety of learners' experiences into the teaching and learning process. For instance, Freire (2000) proposed a "problem-posing education model" which requires teachers to adopt a dialogic and context-specific approach in teaching focusing on learners' social, political and cultural experiences (p. 80). A teaching approach like this fosters learners' agency and allows them to take charge of their own learning. However, the teaching approaches in the current EFL classrooms occasionally provide learners with the opportunity to exercise their agency, since only parts of their life experiences are taken into account. Hence, there is an urgency for EFL teachers to adopt CDP in their classrooms to ensure that learners are learning autonomously through dialogic exchanges and that their individual experiences are being considered as valuable additions to the classroom in order to challenge the existing power dynamics and stand against oppression.

Since CDP is a comparatively new approach to education, there seems to be an absence of a fixed definition and an elaborate model for implementing CDP in the EFL classrooms. This study aims to address these issues by reviewing the existing research studies on $\mathrm{CP}, \mathrm{CDP}$ and the implementation of CDP in EFL classrooms in different contexts. It also presents a critical review of the existing models of $\mathrm{CP}$ and $\mathrm{CDP}$ to provide a comprehensive understanding of its core concepts and to examine its relevance in the current educational scenario. The study will further propose a prospective model, revised and summarized from previous models, for providing practitioners with a working format for implementing CDP in EFL classrooms. The principal objective of this study is to provide EFL practitioners, researchers, policy makers and stakeholders with the basic understanding of CDP for assisting them to consider the implementation of this pedagogy in EFL classrooms during this pandemic as well as in the future.

\section{Literature review}

\subsection{Origin of critical digital pedagogy}

The origin of CDP dates back to the 1970s. Paulo Freire introduced the concept of CP through his book, Pedagogy of the Oppressed in 1968. Though written in Portuguese initially, it was published in English a year later in 1970. In this book, Freire proposed a pedagogy for the victims of oppression which aims at addressing the "duality" prevalent among the oppressed (Freire, 2000, p. 48). Despite realizing that authenticity cannot be achieved in life without freedom, the oppressed are often in fear of dissociating themselves from the oppressor's ideals or reality (Freire, 2000). According to Freire, only education can eradicate this dilemma if a pedagogy is formed "not for" but "with the oppressed" with the goal of reviving their critical consciousness (Freire, 2000, p. 48). A pedagogy like this will not only make the 
oppressed reflect upon the causes of the oppression, but they will also engage themselves in fighting for their liberation (Freire, 2000).

The pedagogy suggested by Freire (2000) stands in contrast to the traditional practices. The Brazilian educator and philosopher criticized the traditional teaching system and compared it with "banking", as students' role in a traditional classroom is like "depositories", where teachers "deposit" knowledge (Freire, 2000, p. 72). "Banking education" destroys students' capability of creative thinking which is a significant obstacle on the way to achieving freedom and reinforces the oppressors' objective of dominating the oppressed intellectually (Freire, 2000, p. 73). In order to transform the "banking" education system and to assist students in fighting such "domestication" induced by their oppressors, educators must partake in their learners' struggle for justice by forsaking the power dynamics of a traditional classroom (Freire, 2000, p. 75).

Freire (2000) proposed the "problem-posing" model to replace the teaching practices of the "banking" model in education. "Problem-posing" education is a liberating pedagogy which creates the scope for teachers and students to embark on a partnership through dialogs, and the teacher is not anymore the "depositor" or the authority in the classroom, rather they are coconstructors of knowledge (Freire, 2000, p. 80). Problems in "problem-posing" education come across as challenges to students and they are forced to respond to these challenges which elicit more challenges (Freire, 2000, p. 80). Responding to challenges and reflecting on the world, their surroundings and themselves, generate critical consciousness in students (Freire, 2000). It acts like a driving force and pushes learners to engage in "the pursuit of full humanity" through solidarity in fighting oppressions and instigating transformation (Freire, 2000, p. 85).

\subsection{Critical pedagogy}

$\mathrm{CP}$, in simple words, is the praxis while Pedagogy of the Oppressed is the method. "Reflection and action" are integral constituents of any praxis; thus $\mathrm{CP}$ requires "reflection and reconceptualization" of the occurrences inside the classroom and the rationales behind that (Freire, 1985, cited in Monchinski, 2008, p. 1). Freire's "critical classroom" does not approve of the method of creating "passive and anti-intellectual" learners (Shor, 1993, p. 25). Freirean teachers are thus critical minds and problem-posers, who ask questions to elicit thoughts and stimulate students' minds to generate questions. Students partake in the knowledge creation process which empowers them and demands their active intellectual participation (Shor, 1993).

Recognizing the presence of politics in every type of pedagogy, CP itself admits being selfevidently political. Like most other pedagogies, $\mathrm{CP}$ is not only about the production of knowledge, rather it addresses the entire education system and all its functionalities altogether and aims at transforming the relationships among classroom teaching, the process of generating knowledge, institutional policies and structures, the dynamics of different social and material connections of a community as well as the country as a whole (Freire, 1985, cited in Monchinski, 2008).

Emphasizing its political and moral influences, Giroux (2011) points out, CP is not just a set of skills or strategies, but it is a context-specific pedagogy which is closely related to the particularities of a community, its resources, the students and their struggles. $\mathrm{CP}$ is an approach to teaching that addresses the entirety of learners' academic and personal experiences and knowledge is co-produced by the students and the teacher in a critical classroom through challenging the predetermined roles and existent power dynamics in a traditional classroom (Giroux, 2011).

$\mathrm{CP}$ in its rawest form is supposed to be the Pedagogy of the Oppressed; however, it does not mean it is limited to only the underprivileged or the oppressed population. Some critical pedagogues reject the idea of involving the privileged groups in eradicating oppression, because the majority of them just only benefit from their privileges and they continue doing
From CP to critical digital pedagogy 
SJLS

1,1

so even if they are standing against oppression. Since people from privileged backgrounds cannot liberate the oppressed by merely participating in a classroom that adopts $\mathrm{CP}$, they should not be a part of it.

On the other hand, some critical pedagogues criticize this stream of belief and point out that focusing on the "oppressed" students and not paying heed to the "oppressor" students do not address the oppression holistically. Pedagogues who deem the reformation of $\mathrm{CP}$ necessary outline the urgency of reinventing and re-envisioning $\mathrm{CP}$ for inducing a "wide-scale transformation for social inequalities" (Allen and Rossatto, 2009, p. 165). Not implementing $\mathrm{CP}$ in classrooms containing middle class and upper-class students will further solidify the practice of oppression and "inhibit the construction of collective consciousnesses" (Allen and Rossatto, 2009, p. 167). Although the oppressed do not need the oppressors to change to liberate themselves from the oppression, the oppressors certainly need to be humanized and gain critical consciousness to redefine their role in the social hegemony. Indeed, it is important for $\mathrm{CP}$ to work with privileged/oppressor students to instigate "significant and radical changes" (Allen and Rossatto, 2009, p. 178).

\subsection{Critical pedagogues and technology}

Critical pedagogues have echoed the same idea of learner empowerment repeatedly in many of their works. Giroux (2009) specifically mentioned the significance of a democratic environment that establishes a platform for students to question and share their experiences using their agency in a critical classroom. When it comes to considering a place that would support a free and liberating exchange of knowledge, cyberspace comes across one such platform. Freire (2014), in fact, did not take a stand against using technology in the praxis of CP. He suggested the importance of being "critical" in the use of technology in the classroom and to utilize it in order to create new channels, methodologies and relationships between learners and technology (cited in Boyd, 2016, p. 167).

Technology can produce creative spaces for the marginalized, who otherwise would not have any channel to make their voices heard. Since the stakeholders of educational institutions focus more on their forms, policies, practices and curriculum, teachers' and students' interaction with these are often overlooked. Virtual platforms do not have these limitations since no group can establish domination over another group. It does not only promote interaction and free exchange of knowledge between students and the teacher, but also inspires innovation and change. Since CP puts much emphasis on dialogical approaches to teaching, cyberspace can provide both teachers and students with the correct platform to engage in dialogs synchronously or asynchronously (Gitlin and Ingerski, 2018).

\subsection{Definitions of critical digital pedagogy (CDP)}

Since CDP is comparatively a newer field of study, it hardly has one definite way of defining it. In simple words, the translation of CP into cyberspace is known as CDP. However, CDP is more elaborate than a mere transition of $\mathrm{CP}$ into the virtual platform. $\mathrm{CDP}$, according to Morris and Stommel (2018), is an open and diverse pedagogy which goes beyond the classroom, focuses upon "community and collaboration" and demands the invention of new ways of crossing "cultural and political boundaries" to welcome a "cacophony of voices" from all around the world (p. 9).

In a CDP classroom the teacher and students do not only engage in a dialogic exchange of opinions and make use of their agency to the fullest extent, but they also critically analyze the characteristics and impacts of using any technological tool in the classroom. Technological tools, learning management systems (LMS) and social media do not dictate teachers and students about how each of these should be used in a classroom, rather teachers and students 
invent ways, techniques and manners of using these tools to suit their purpose, beliefs, practices and philosophy (Morris and Stommel, 2018).

The principal emphasis of CDP is on creating an open and liberating digital space for learning which will assign the roles of critical co-investigators of knowledge to both students and teachers to break free from the age-old traditional banking education system where the teacher is the only knowledgeable individual in the classroom and the students are knowledge-gatherers. The digital platform is an ideal empowering space that gives learners the free access to deconstruct, elaborate and critique any sort of knowledge. Digital tools like Google Docs and other similar software give learners and teachers the opportunity of writing and working together, thus co-creating knowledge. It diminishes the hierarchical environment of a traditional classroom and creates a platform for collaboration. An open platform like cyberspace endorses collaboration in problem-posing education by engaging learners and teachers in discussions, which is a practice that stands in contrast to the traditional banking education system (Rosen and Smale, 2015).

Due to being a new field of research and the availability of a limited number of research studies, the definition of CDP is still under construction. Morris and Stommel (2018) have encouraged researchers to come forward and define CDP according to their individual interpretations as it cannot be done by them only. As researchers have access to a limited number of literature studies along with a lack of clear concepts, it is definitely a challenge on the way of conducting elaborate research and even a bigger challenge for practitioners who plan to implement CDP in their classroom. However, the available case studies and discussions can prove to be helpful for current and future researchers to understand and analyze the implementation of CDP in a number of different contexts.

\subsection{CDP in the current situation of the world}

The implementation of CDP in the classroom has become more relevant than ever in the current pandemic-afflicted world. COVID-19 was first identified in Wuhan, China in December 2019, which is a respiratory disease caused by a type of coronavirus that spreads rapidly through people's breath, sneeze, cough and every other type of close contact. It broke out in January 2020 and the World Health Organization declared it to be a pandemic in March 2020. It was then that the South Asian countries announced a nationwide lockdown that resulted in the indefinite closure of many organizations and offices including all types of educational institutions (Sun et al., 2020).

To battle exceptional circumstances like these, countries all across the world suspended face-to-face classes and introduced synchronous and asynchronous delivery of lessons via the Internet (Moorehouse, 2020). Since March 2020 till date (March 2021), most of the countries across the world have been using cyberspace as the virtual classroom for students of all levels and educational institutions. Conducting online classes through video conferencing software such as Google Meet, Microsoft Teams and Zoom providing learners with instructions, learning resources and materials through a variety of LMS such as Moodle, Google Classroom, Blackboard, Discord, etc. have been the regular practice all around the world throughout this one year. Simple digital tools such as PowerPoint slides and emails had very limited and specific use prior to the pandemic. The pandemic has forced educators and students alike to make use of a variety of tools and critically think about the implementation of these in the classroom (Moorehouse, 2020).

Nevertheless, a drastic transformation like this does not come without its challenges. The lack of training on the use of digital tools for students and teachers paired with unstable Internet connection, especially in remote and underdeveloped regions, have resulted in continuous disruption in synchronous and asynchronous delivery of lessons and instructions (Morris et al., 2020). Therefore, it would not be an overstatement to say that CDP is more

From CP to critical digital pedagogy 
SJLS

1,1

relevant now than ever before. $\mathrm{CDP}$, as indicated earlier, is not only about implementing $\mathrm{CP}$ into cyberspace, but it is also about considering the use of technology to benefit teachers and students and not being blindly guided and directed by it. CDP requires educators to inspect, understand, read about and reflect upon the use of technological tools before implementing them in their classroom (Morris et al., 2020).

Many digital tools that are now widely being used around the world were not developed for facing an unprecedented crisis like this. Edtech in general was not built for interacting with humans, rather to interact with other technological resources to collect information and create a reservoir of data (Morris et al., 2020). Thus, there is an urgency to adopt CDP in our classrooms to humanize technology in order to serve our purpose of promoting freedom and creating a more humane educational environment (Freire, 1973, cited in Morris et al., 2020, p. 23).

\subsection{Critical digital pedagogy in global contexts}

As stated earlier due to a limited number of literature studies and research, the practices of $\mathrm{CDP}$ are still abstract to a certain degree and the application and implementation of CDP in the classroom are still open to individual practitioners' interpretation (Bali, 2020). While this freedom of thinking provides educators with the opportunity to experiment and exercise their critical consciousness, it also leaves the practice subjective with little guidelines for future practitioners to follow. However, some case studies recorded in several published research studies provide some insight into how CDP can be implemented in the classroom.

Waddell and Clariza (2018) mention the case study of a classroom at the University of Hawaii at Mānoa, where CDP was implemented using infographics and digital storytelling. Since the university contains learners from a number of countries, it provides the educator with an opportunity to endorse international voices in the classroom. While learners are encouraged to create their own infographics focusing on science research topics in this classroom, it is not only limited to that. Since CDP and CP recommend addressing the entirety of learners' experiences, students take into account how science topics are related to their "personal cultural experiences and identity" (Waddell and Clariza, 2018, p. 229). Prior to creating their own infographics, learners also analyze and discuss infographics collected from different sources, which promotes collaboration and interaction. In addition, learners reflect upon the "power structures and cultural dynamics" involved with generating and conveying scientific information with an increasingly technology-driven society in general (Waddell and Clariza, 2018, p. 230). The reflection focuses on the oppression caused by withholding significant scientific information from the ordinary public by publishing them only in authorized journals and thus exercising power and authority.

Moreover, digital storytelling works as an effective medium of empowering learners as it involves learners in reading, writing, listening and speaking which provides the marginalized population of the society with the opportunity of sharing their "experiential knowledge" (Waddell and Clariza, 2018, pp. 230-231). By using a variety of digital tools, learners can share their experiences collaboratively in the form of a story using pictures, videos, writings etc. Learners appreciate this technique as it helps them acquire a better understanding of their own culture and community as well as makes them feel empowered because of the critical viewpoint they adopt to analyze their personal histories in relation to the existing power structures. (Waddell and Clariza, 2018).

Bali (2020) mentions a case study of an Egyptian undergraduate classroom where she has been giving lessons as a teacher and her teaching philosophy revolves around CDP. She emphasizes the importance of discussions on the role of digital tools in ensuring social justice in her classroom. She encourages her students to dissent respectfully and teaches "digital agnosticism" so that her students are not driven by technology, rather they evaluate the 
implementation of any technology critically (Bali, 2020; para. 3). Students' taking charge of their own learning and bringing their socio-economic, socio-political and socio-cultural experiences in the classroom, help them to learn from each other. The author thus encourages her students to take a stance against social injustices and challenges the status quo. By giving students the authority to address her and each other by their first names, she strives toward creating a dialogic learning environment where traditional power dynamics have been uprooted (Bali, 2020).

However, all these innovative measures toward implementing CDP in the classroom do not always receive students' approval. In the Egyptian classroom, students' think that the teacher is withholding information by not delivering knowledge as is done in a traditional classroom. Students do not always understand the concept of co-creating knowledge and the value of sharing the knowledge they have. The teacher learning from students also comes across as an opportunistic act to the students, as they think the teacher is using the class environment to collect research data. In addition, instead of sharing their inherent knowledge, students at times decide to plagiarize which can extract a coerce authoritative reaction from the teacher that may destroy the equilibrium in the classroom achieved through CDP (Bali, 2020).

Even on social injustice related topics on gender discrimination, a number of male students at times have the tendency of being assertive of their authority and dominance over women, which leads to heated debates between male students and female students. Older students in a class may take up more authority than the younger members, thinking their age demands more respect than they are ready to give others. The same phenomenon may be noticed when seemingly privileged students who come from more developed backgrounds take over the group discussion and students who do not come from such privileged backgrounds are subconsciously silenced (Bali, 2020).

\subsection{CDP in teaching English as a foreign language}

Due to its novelty, there is a general scarcity of literature written on the implementation of $\mathrm{CDP}$ in an EFL context. Nevertheless, researchers and practitioners have experimented with the implementation of CP in English classrooms all around the world, including in Asian classrooms of Japan, South Korea and Indonesia. The prevalent skepticism regarding the probable conflict between CP and ELT proved to be non-existent as teachers applied the pedagogy in their classrooms. Teachers acknowledge the importance of having an open and workable curriculum to provide students with the opportunity of having their say in making choices in the knowledge construction process. Teachers from Japan and Korea engage in discussions with their students on topics like gender discrimination, racism, sexism, etc. in other words, topics that are mostly based on social injustices (Larson, 2014).

Wallerstein (1982) particularly emphasizes the importance of "problem-posing" education in EFL classrooms, as according to him, "Problem-posing is a group process that draws on personal experience to create social connectedness and mutual responsibility" (p. 34). While the author acknowledges that the pedagogy is best fitted for immigrants, he also recognizes its importance with students from underprivileged or challenging backgrounds who face discrimination in their everyday life and the empowering dialogic learning environment of their English classroom can equip them with a better understanding of their circumstances to challenge the social structure (Wallerstein, 1982).

The three principal phases of the problem-posing education are of particular importance according to Wallerstein (1982), namely, investigating social injustices through "listening", engaging in discussions through "dialogue" and determining "actions" for bringing changes into the society through reflections (p. 35). All the three phases of problem-posing education highlight two key skills of language learning, speaking and listening. Learners can develop

From CP to critical digital pedagogy 
SJLS

1,1

their speaking skills further by producing speeches in dialogic discussions and improve their comprehension skills through listening to their peers and teacher while investigating social injustices. The other two receptive and productive skills, namely, reading and writing, can also be successfully implemented in a CP classroom through textual analysis of social issues or the written articulation of learners' stance. In this way, learners do not develop only the four key skills of learning a language, but they also exercise their "higher order thinking skills", in other words, "Critical Thinking" skills that requires them to involve in a logical and reasonable in-depth thinking process (Ennis, 1985, p. 45).

Wallerstein (1982) also mentions the importance of "a concrete physical representation of a particularly critical issue" which he terms as "codes" (p. 38). Codes can be a plethora of resources, ranging from images, visual cues to dialogs, stories, songs etc. A code is particularly helpful in a CP classroom as it is a concrete portrayal of the problem which allows learners to approach it from different perspectives and provide them with the opportunity to analyze it in their individual ways (Wallerstein, 1982). In the digital age, codes can be blogs, videos, infographics, charts, tables, etc. depending on the context and logistic support available to the teacher and students.

\section{CDP models}

\subsection{CDP model in online education}

Freire's works suggested the importance of a problem-posing education model in order to replace the traditional banking education system. His model, although not specific and detailed, worked as the foundation for practitioners and researchers on which they could build their individual models for years. McLaren (1999) outlined six learning principles from Freire's works that can work as a set of guidelines for researchers and practitioners when they develop their own models. The six principles are as follows:

(1) Learners should aim at learning about the world through their own efforts and their interpretation of knowledge should be centered on their individual experiences, necessities, circumstances and objectives.

(2) Learners should approach the history and the culture of the world as an everchanging and prone to transformation reality that is under construction and continuously changing according to human ideology and their contribution.

(3) Learners should internalize the strategies of making connections between their own circumstances and the existence and construction of reality actively.

(4) Learners should acknowledge the potential of reconstructing reality and the prospective outcomes that can be derived from such a reconstruction. They should be determined to make their voices heard and take part in building a novel empowering and rejuvenating history in collaboration.

(5) Learners will learn the significance of putting their collaborative projects into print. Acquiring the competence and literacy of publishing their ideas, experiences, and interpretation in public domains through "active construction and reconstruction" will help learners realize the importance of their voice as human beings.

(6) Learners will further realize the existing myths in popular discourses along with the ones that "oppress and marginalize" them which can be overcome and transformed through their changemaking actions (p. 51).

Following the above-mentioned principles critical digital pedagogues have presented their model for teaching and learning on the virtual platform. MOOCs or massive open online 
courses are effective online learning platforms for promoting teachers' and learners' agency in higher education (Morris and Stommel, 2017). These sites can be liberating for learners and teachers as they are free from institutional policies and restrictions and often have a more open and unrestricted curricula. However, since technology does not have human values integrated into it, digital tools and platforms may become our dictator and leave no scope for using our agency if we are not attentive toward evaluating them critically.

Despite having the potential of stimulating learners' agency and expanding network and collaboration, MOOCs can turn into oppressors by aiming at depositing knowledge in students and not paying heed to learners' autonomy and experiences. MOOCs turn the learning platform as a content-led platform and contents replace the teacher, as a result, the teachers are absent, and teachers and students cannot shift into each other's roles, which is necessary for a CDP classroom (Morris and Stommel, 2017).

To fight these challenges, MOOCs should adopt building empowered communities as their prime objective, not mere reservoirs of content (Morris and Stommel, 2017). Morris and Stommel (2017) recommend a "connectivist MOOC model" based on one MOOC they developed and launched, which renders learners the opportunity to connect with each other. As they are mostly unstructured, connectivist MOOCs can leave students baffled if left entirely on their own. Therefore, even on MOOCs teachers cannot fully disappear, they should be present as co-creators of knowledge and thus it does not leave MOOCs "leaderless but leader saturated" (Morris and Stommel, 2017, p. 187). Rather than leaving teachers out of the picture or giving the sole authority of imparting knowledge to the course content, MOOCs can include incomplete or thought-provoking content so that learners can create the complete content by themselves by asking questions and using their agency to find out the answers (Morris and Stommel, 2017).

\subsection{The connectivist CDP model in an EFL classroom}

Since connectivism recognizes "learning as a network phenomenon influenced by technology and socialization", its applicability in any digital pedagogy including CDP is relevant and practical as it promotes learning as a community endeavor (Goldie, 2016, p. 1). According to the connectivist model, the four basic components of a strong learning network are diversity in the network, participants' autonomy, openness of perspectives and connections between the learning community and other sources of information (Goldie, 2016). Most importantly, connectivism acknowledges that knowledge is not located in any particular source, rather knowledge is constructed through interactions between individuals and societies, and technology or digital tools play the role of establishing connections between them (Goldie, 2016). The proximity between the philosophies and beliefs of connectivism and CDP make the two interconnected and the necessity of linking the two in creating a model for CDP is concretely evident. Thus, analyzing the previous models and finding basis in the six principal theses mentioned by Morris and Stommel (2017), a working model for CDP has been outlined below.

The six principal theses proposed by Morris and Stommel (2017) for their "connectivist MOOC model" are as following:

(1) Courses should be dialogic and not mere storehouses of contents,

(2) Education cannot be forced upon students, they exercise their own agency to learn,

(3) Educators should not run after "best practices", they should rather focus on "meeting and working mindfully and collectively with students",

(4) Courses should not have predetermined outcomes and learners will decide upon the outcomes as they continue constructing knowledge and reflect upon them,

From CP to critical digital pedagogy 
SJLS

1,1
(5) Learning should not be structured and guided based on assessments,

(6) Teachers and students will co-construct knowledge together by thinking critically about technology, institutions, policies, oppressions and sufferings thus engaging in a liberating form of education (pp. 189-195).

Based on the aforementioned six principles, it is safe to infer that in a CDP classroom model there is no room for lecture-based classes or assessment-led curriculum. The traditional lectures must be replaced by dialogs in a CDP classroom and assessments should be based on reflections and critical thinking. The following discussion presents a prospective model for applying CDP in English as a foreign language classroom.

(1) Learning outcomes/objectives: Unlike a traditional classroom, learning outcomes/ objectives cannot be predetermined in a CDP classroom. Learning outcomes or objectives are something the students will decide through reflection and critical thinking as they go through the dialogic process of learning (Morris and Stommel, 2017).

(2) Curriculum: In a CDP classroom there is no fixed curriculum and whatever the curriculum transpires to be, it must be "flexible and negotiable" (Bali, 2020; para. 3). In a CDP classroom, students and teachers work together to develop their own curriculum through dialogic exchanges. The curriculum is open and adjustable, and it keeps forming as teachers and students go through the learning process.

(3) Content: As Freire suggested, CP classrooms follow the problem-posing education model where students and teachers co-create knowledge (Freire, 1972). The problemposing education model has a certain degree of similarity with problem-based learning which requires learners to find answers to questions and critically think about real-life problems and work toward solving them by determining their action (Hung et al., 2008). CDP emphasizes the necessity of ensuing discussions on social injustices and asking questions in order to provide students with the opportunity to articulate their opinions on these oppressions based on their individual social, cultural and political experiences. The teacher also partakes in these discussions and through questions and answers and dialogic exchanges they get a holistic picture on the issue (Freire, 1972).

(4) Language skills: Since CDP is a pedagogy that is applicable in all disciplines, regardless of the subjects and concentrations, language teachers may find it difficult to integrate CDP in their classroom without any specific set of instructions on lesson delivery. However, as English language teaching and learning are not content-bound, EFL teachers have the advantage of implementing CDP in their classroom without having to be concerned about meeting course requirements. CDP can be applied to all activities in reading, writing, speaking and listening by allowing learners to voice their opinions and share their experiences orally and through writing, as well as read about the prevalent oppressions and social injustices and listen to different perspectives to comprehend the ideas through critical thinking and engage in critiquing them from their own perceptions (Waddell and Clariza, 2018).

(5) Collaboration: Collaboration and learning as a community are the essence of CDP. Unity through diversity empowers students to create a global community with their peers from different cultural and social backgrounds and helps them learn from each other. Peer discussions and peer feedback are significant parts of a CDP classroom as they provide the authority of learning to students. The teacher also becomes a part of 
this collaboration and takes part in this educational movement equally with students. CDP is primarily a social justice movement and secondarily an educational movement, therefore, community and collaboration are compulsory components of it (Morris and Stommel, 2018).

(6) Assessment and evaluation: As advocated by critical pedagogues, there is no space for assessments in a CDP classroom, and neither the curriculum nor the classes can be led or structured by assessments. Students' progress in a CDP classroom is selfevaluated by students through reflection and critical thinking. Students will reflect upon their progress from the first day of the course till the last day and determine what learning outcomes they have achieved as they continue their classes. Teachers will help them in reflecting and participate with them throughout the process of selfevaluation (Morris and Stommel, 2017).

(7) Digital tools: The use of digital tools in a CDP classroom mostly depends on the discretion of the teachers and students. As Bali (2020) suggested, learners and teachers have to be critical about the use of digital tools in the classroom and determine the implementation of these tools by themselves and not be driven by the tools. Being critical about the use of digital tools is an integral part of CDP and teachers and students must ensure that they are using platforms that allow "a free flow of knowledge" (Kellner and Kim, 2010, p. 5). Among the new media, MOOCs, blogging, social media platforms like Facebook and twitter and video conferencing software provide learners with the opportunity of articulating their opinions freely and openly without being restricted by their institutions or curricula. In addition, it provides learners with an international audience, and unlike the closed environment of a physical classroom, they get a real opportunity to voice their stance against social injustices and exercise their power and authority coming out of all types of social restrictions. The aforementioned model is an open and adjustable model proposed for interested practitioners and researchers to provide them with an insight into the core concepts of a potential CDP classroom. In alignment with the philosophy of Freire's $\mathrm{CP}$, it is amendable according to the requirements and needs of different contexts and its implementation entirely depends on teachers' and learners' collaborative discretions in a CDP classroom.

\section{Conclusion and recommendations}

This paper outlines the key literature studies on CDP and briefly highlights some core concepts of $\mathrm{CP}$ and the Pedagogy of the Oppressed. CDP, as mentioned by its principal advocates, cannot be defined or interpreted by individual researchers or practitioners alone. In the same way, there cannot be one principal model or a set of standardized practices in CDP as it is against Freire's philosophy of establishing and empowering and dialogic pedagogy. The role of technology and the choice of digital tools also depend on a number of factors and the practices that worked in one context are mostly unlikely to work in others. Therefore, it is necessary for practitioners and researchers to take these cultural, demographic and contextual factors into account to gain a proper understanding of the affordances and limitations of CDP in their individual contexts.

One of the limitations of CDP is gaining the learners' approval in creating an environment of co-constructing knowledge moving away from traditional practices. In addition to that the use of new media in the classroom can be intimidating for students and stakeholders alike. The lack of logistic support in many rural, remote and underdeveloped contexts cannot be ignored either. Hence, a balanced and more practical attempt to CDP would be implementing it through the blended learning approach which basically refers to the thoughtful

From CP to critical digital pedagogy 
SJLS

1,1

implementation of digital tools with face-to-face classroom practices (Garrison and Kanuka, 2004, p. 97). Although in the current situation of the world a blend between physical classroom activities and virtual classroom tasks is not entirely possible, a blend between different activities and group projects with classroom discussions can make the implementation of CDP in classroom more acceptable to all the concerned parties until the world goes back to its normal state. In short, CDP is a flexible approach to teaching which challenges the traditional classroom practices and aims at empowering students by giving them the opportunity of voicing their stance against oppression and strive collaboratively toward establishing social justice, and to achieve this, researchers and practitioners need to come forward and work collaboratively toward reaching the goal through research and practice.

\section{References}

Allen, R.L. and Rossatto, C.A. (2009), "Does critical pedagogy work with privileged students?", Teacher Education Quarterly, Vol. 36 No. 1, pp. 163-180, available at: https://www.jstor.org/ stable/23479207?seq=1 (accessed 13 March 2021).

Bali, M. (2020), "Critical pedagogy: intentions and realities", in Morris, S.M., Friend, C. and Stommel, J. (Eds), Critical Digital Pedagogy: A Collection, available at: https://cdpcollection.pressbooks.com/ front-matter/introduction/ (accessed 13 March 2021).

Barnes, D. (1992), From Communication to Curriculum, Boynton/Cook, Portsmouth, NH.

Boyd, D. (2016), "What would Paulo Freire think of Blackboard: critical pedagogy in an age of online learning", The International Journal of Critical Pedagogy, Vol. 7 No. 1, available at: http:// libjournal.uncg.edu/ijcp/article/view/1055 (accessed 13 March 2021).

Ennis, R.H. (1985), "A logical basis for measuring critical thinking skills", Educational Leadership, Vol. 43 No. 2, pp. 44-48, available at: https://jgregorymcverry.com/readings/ ennis1985assessingcriticalthinking.pdf (accessed 13 March 2021).

Freire, P. (1972), Pedagogy of the Oppressed, 1968, Trans. Myra Bergman Ramos, Herder, New York.

Freire, P. (2000), Pedagogy of the Oppressed, 30th anniv. ed., Continuum, New York, p. 35.

Garrison, D.R. and Kanuka, H. (2004), "Blended learning: uncovering its transformative potential in higher education", The Internet and Higher Education, Vol. 7 No. 2, pp. 95-105, available at: https:// www.sciencedirect.com/science/article/abs/pii/S1096751604000156 (accessed 13 March 2021).

Giroux, H. (2009), "The challenge and promise of critical pedagogy in the new information age: an interview with Henry Giroux", Teoría de la Educación. Educación y Cultura en la Sociedad de la Información, Vol. 10 No. 3, pp. 243-255, available at: https://www.redalyc.org/pdf/2010/ 201014898015.pdf (accessed 13 March 2021).

Giroux, H.A. (2011), On Critical Pedagogy, Continuum, New York, NY.

Gitlin, A.D. and Ingerski, J. (2018), "Rewriting critical pedagogy for public schools: technological possibilities", The International Journal of Critical Pedagogy, Vol. 9 No. 1, available at: http:// libjournal.uncg.edu/ijcp/article/view/1394 (accessed 13 March 2021).

Goldie, J.G.S. (2016), "Connectivism: a knowledge learning theory for the digital age?", Medical Teacher, Vol. 38 No. 10, pp. 1064-1069, available at: https://www.tandfonline.com/doi/abs/10. 3109/0142159X.2016.1173661 (accessed 13 March 2021).

Hung, W., Jonassen, D.H. and Liu, R. (2008), "Problem-based learning", Handbook of Research on Educational Communications and Technology, Vol. 3 No. 1, pp. 485-506, available at: https:// www.academia.edu/download/50946792/PBL_Ch38_AECT_Handbook_ed3.pdf (accessed 13 March 2021).

Kellner, D. and Kim, G. (2010), "YouTube, critical pedagogy, and media activism", The Review of Education, Pedagogy, and Cultural Studies, Vol. 32 No. 1, pp. 3-36, available at: https://www. tandfonline.com/doi/full/10.1080/10714410903482658 (accessed 13 March 2021). 
Larson, K.R. (2014), "Critical pedagogy (ies) for ELT in Indonesia”, TEFLIN Journal, Vol. 25 No. 1, pp. 122-138, available at: http://journal.teflin.org/index.php/journal/article/view/186 (accessed 13 March 2021).

McLaren, P. (1999), "Research news and comment: a pedagogy of possibility: reflecting upon Paulo Freire's politics of education: in memory of Paulo Freire", Educational Researcher, Vol. 28 No. 2, pp. 49-56, available at: https://journals.sagepub.com/doi/abs/10.3102/0013189x028002049 (accessed 13 March 2021).

Monchinski, T. (2008), "Critical pedagogy in the everyday classroom", in Critical Pedagogy and the Everyday Classroom, Springer, Dordrecht, pp. 115-139, available at: https://ink.springer.com/ chapter/10.1007\%2F978-1-4020-8463-8_4 (accessed 13 March 2021).

Moorhouse, B.L. (2020), "Adaptations to a face-to-face initial teacher education course 'forced' online due to the COVID-19 pandemic", Journal of Education for Teaching, Vol. 46 No. 4, pp. 609-611, available at: https://www.tandfonline.com/doi/full/10.1080/02607476.2020.1755205 (accessed 13 March 2021).

Morris, S.M. and Stommel, J. (2017), "Open education as resistance: MOOCs and critical digital pedagogy”, MOOCs and their Afterlives: Experiments in Scale and Access in Higher Education, Vol. 177, available at: https://books.google.com.bd/books?hl=en\&lr=\&id=S5YtDwAAQBAJ $\& o \mathrm{i}=$ fnd\&pg $=$ PA177\&dq $=$ Morris,+ S. + M. + and + Stommel,+ J., $+2017 .+$ Open + education + as + resistance: + MOOCs + and + critical + digital + pedagogy $.+\& o t s=$ DKslhYsK1\&sig $=$ K9y6YS NqKkciL76Xd7k95K3hNY\&redir_esc=y\#v=onepage\&q\&f=false (accessed 13 March 2021).

Morris, S.M. and Stommel, J. (2018), An Urgency of Teachers: The Work of Critical Digital Pedagogy, Hybrid Pedagogy.

Morris, S.M., Friend, C. and Stommel, J. (2020), "The urgency of critical digital pedagogy”, in Morris, S.M., Friend, C. and Stommel, J. (Eds), Critical Digital Pedagogy: A Collection, Hybrid Pedagogy.

Rosen, J.R. and Smale, M.A. (2015), Open Digital Pedagogy= Critical Pedagogy, available at: https:// academicworks.cuny.edu/cgi/viewcontent.cgi?article $=1682 \&$ context $=$ ny_pubs (accessed 13 March 2021).

Shor, I. (1993), "Paulo Freire's critical pedagogy", Paulo Freire: A Critical Encounter, Vol. 23, available at: https://books.google.com.bd/books?hl=en\&lr=\&id=JeiJAgAAQBAJ\&oi=fnd\&pg=PA2 $4 \& \mathrm{dq}=$ shor + ira $+1993 \&$ ots $=7$ Nmnygaewx \&sig $=$ PsqeJiY7GU9Pm_ZYOeR6DZ4z7ok\&redir_ $\mathrm{esc}=\mathrm{y} \# \mathrm{v}=$ onepage \&q\&f$=$ false $($ accessed 13 March 2021).

Sun, J., He, W., Wang, L., Lai, A., Ji, X., Zhai, X. and Veit, M. (2020), “COVID-19: epidemiology, evolution, and cross-disciplinary perspectives”, Trends in Molecular Medicine, Vol. 26 No. 5, pp. 483-495, available at: https://www.sciencedirect.com/science/article/abs/pii/ S1471491420300654 (accessed 13 March 2021).

Waddell, M. and Clariza, E. (2018), "Critical digital pedagogy and cultural sensitivity in the library classroom: infographics and digital storytelling", College and Research Libraries News, Vol. 79 No. 5, p. 228, available at: https://crln.acrl.org/index.php/crlnews/article/view/16963 (accessed 13 March 2021).

Wallerstein, N. (1982), "Language and culture in conflict", Problem-Posing in the ESL Classroom, available at: https://eric.ed.gov/?id=ED221043 (accessed 13 March 2021).

\footnotetext{
About the authors

Marwa Mohammad Masood is an Assistant Professor in the English Language Institute at United International University, Bangladesh. Ms Masood completed her second Master's in TESOL from the University of Warwick. In 2015, she completed her first Master's in English from North South University and the previous year she graduated in English Language and Literature from International Islamic University Chittagong. Her research interests include critical pedagogy, ICT in TESOL and Teacher Education and Development.

Md. Mahmudul Haque is a lecturer in English at Faculty of Languages and Translation, King Khalid University, Saudi Arabia. He was a Fulbright exchange scholar at University of Georgia, USA in 2009-2010. He earned his BA and MA in English from University of Rajshahi, Bangladesh. He completed Cambridge
} 
SJLS

1,1
CELTA in 2017. He is currently enrolled in a doctoral program of Applied Linguistics at Faculty of Languages and Linguistics, University of Malaya, Malaysia. His research interests include learner autonomy, metacognition, languages learners' beliefs, code-mixing and communicative language teaching. Md. Mahmudul Haque is the corresponding author and can be contacted at: malhg@kku.edu.sa

For instructions on how to order reprints of this article, please visit our website: www.emeraldgrouppublishing.com/licensing/reprints.htm Or contact us for further details: permissions@emeraldinsight.com 